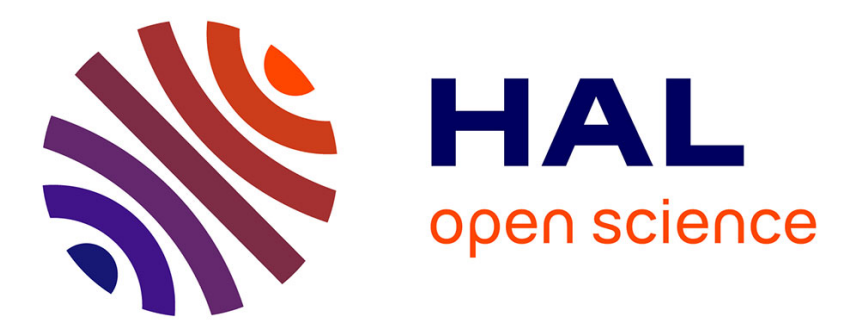

\title{
Association between hospital-diagnosed atopic dermatitis and psychiatric disorders and medication use in childhood
}

I Vittrup, y M F Andersen, Catherine Droitcourt, L Skov, A Egeberg, M C Fenton, P Mina-Osorio, S Boklage, J P Thyssen

\section{To cite this version:}

I Vittrup, y M F Andersen, Catherine Droitcourt, L Skov, A Egeberg, et al.. Association between hospital-diagnosed atopic dermatitis and psychiatric disorders and medication use in childhood. British Journal of Dermatology, 2021, 185 (1), pp.91-100. 10.1111/bjd.19817 . hal-03129772

\section{HAL Id: hal-03129772 \\ https://hal.science/hal-03129772}

Submitted on 19 Feb 2021

HAL is a multi-disciplinary open access archive for the deposit and dissemination of scientific research documents, whether they are published or not. The documents may come from teaching and research institutions in France or abroad, or from public or private research centers.
L'archive ouverte pluridisciplinaire HAL, est destinée au dépôt et à la diffusion de documents scientifiques de niveau recherche, publiés ou non, émanant des établissements d'enseignement et de recherche français ou étrangers, des laboratoires publics ou privés. 
DR IDA VITTRUP (Orcid ID : 0000-0002-3192-6135)

DR YUKI M F ANDERSEN (Orcid ID : 0000-0001-6131-2815)

DR CATHERINE DROITCOURT (Orcid ID : 0000-0001-6714-6643)

DR LONE SKOV (Orcid ID : 0000-0002-4784-9680)

DR ALEXANDER EGEBERG (Orcid ID : 0000-0001-8257-1816)

Article type : Original Article

Association between hospital-diagnosed atopic dermatitis and psychiatric disorders and medication use in childhood

I. Vittrup, ${ }^{1,2}$ Y.M.F. Andersen, ${ }^{1,2}$ C. Droitcourt, ${ }^{1,2,3,4}$ L. Skov, ${ }^{1,2}$ A. Egeberg, ${ }^{1,2}$ M.C. Fenton, ${ }^{, *}$ P. Mina-Osorio, ${ }^{6 \dagger}$ S. Boklage ${ }^{6 \ddagger}$ and J.P. Thyssen ${ }^{7}$

${ }^{1}$ Department of Dermatology and Allergy, Herlev and Gentofte Hospital, University of Copenhagen, Hellerup, Denmark

${ }^{2}$ Copenhagen Research Group for Inflammatory Skin (CORGIS), Herlev and Gentofte Hospital, Hellerup, Denmark

${ }^{3}$ Department of Dermatology, CHU Rennes, F35000 Rennes, France

4University of Rennes, EA 7449 REPERES “Pharmacoepidemiology and Health Services Research", F35000 Rennes, France

${ }^{5}$ Formerly Sanofi Genzyme, Cambridge, MA, USA 
${ }^{6}$ Formerly Regeneron Pharmaceuticals, Tarrytown, NY, USA

7 Department of Dermatology and Venereology, Bispebjerg Hospital, University of Copenhagen, Denmark

* Current Affiliation: Syneos Health, Boston, MA, USA

${ }^{+}$Current Affiliation: Aurinia Pharmaceuticals, Victoria BC, Canada

$\ddagger$ Current Affiliation: GlaxoSmithKline, Collegeville, PA, USA

Running head: Atopic dermatitis, psychiatric disorders and medications in children

Corresponding author: Jacob P. Thyssen

Email: jacob.pontoppidan.thyssen@regionh.dk

Funding sources: The study was sponsored by Sanofi and Regeneron Pharmaceuticals, Inc.

Declaration of interests: Dr. Vittrup has received salary from funding associated with this study from Sanofi and Regeneron Pharmaceuticals, Inc. Dr. Andersen has received research funding from AP Møller Foundation and the $\mathrm{Kgl} \mathrm{Hofbundtmager} \mathrm{Aage} \mathrm{Bang} \mathrm{Foundation.} \mathrm{Dr.} \mathrm{Droitcourt} \mathrm{has} \mathrm{received} \mathrm{Honoria} \mathrm{from}$ Sanofi-Genzyme. Dr. Skov has been a paid speaker for AbbVie, Eli Lilly, Novartis, and LEO Pharma, and has been a consultant or has served on Advisory Boards with AbbVie, Janssen Cilag, Novartis, Eli Lilly, LEO Pharma, UCB, Almirall, and Sanofi. She has served as an investigator for AbbVie, Sanofi, Janssen Cilag, Boehringer Ingelheim, AstraZeneca, Eli Lilly, Novartis, Regeneron, and LEO Pharma, and has received research and educational grants from Novartis, Sanofi, Janssen Cilag, and LEO Pharma. Dr. Egeberg has received research funding from Pfizer, Eli Lilly, the Danish National Psoriasis Foundation, and the $\mathrm{Kgl}$ Hofbundtmager Aage Bang Foundation, and honoraria as consultant and/or speaker from AbbVie, Almirall, Leo Pharma, Samsung Bioepis Co., Ltd., Pfizer, Eli Lilly and Company, Novartis, Galderma, Dermavant, Bristol-Myers Squibb, Mylan, UCB, and Janssen Pharmaceuticals. Dr. Thyssen has attended advisory boards for Sanofi-Genzyme, Regeneron, LEO Pharma, Union Therapeutics, Pfizer, AbbVie and Eli Lilly \& Co, and received speaker honorarium from LEO Pharma, Regeneron, Abbvie and Sanofi-Genzyme, and been an investigator for Sanofi-Genzyme, Eli Lilly \& Co, LEO Pharma, Pfizer and AbbVie. Miriam 
Fenton was an employee of Sanofi at the time of this study. Susan Boklage and Dr. Paola Mina-Osorio were employees of Regeneron Pharmaceuticals, Inc. at the time of this study.

\section{What's already known about this topic?}

- Children with atopic dermatitis have reduced quality of life, but, besides the well-established association with attention deficit hyperactivity disorder, little is known about psychiatric diagnoses and treatments in association with pediatric atopic dermatitis.

\section{What does this study add?}

- Risk of psychotropic medication use, of consulting a psychiatrist or psychologist, and of being diagnosed with ADHD was higher in children with hospital-diagnosed atopic dermatitis.

Children with hospital-diagnosed atopic dermatitis did however not have higher risk of receiving a hospital-diagnosis of depression, anxiety or self-harming behavior. 


\section{Abstract}

Background: While adult atopic dermatitis (AD) is associated with anxiety and depression and pediatric $A D$ is linked to attention deficit hyperactivity disorder, the relationship between $A D$ in childhood and other psychiatric disorders is largely unknown. Objectives: To determine the relationship between AD and diagnosis and treatment of psychiatric disorders in children. Methods: All Danish children born between January 1 $1^{\text {st }}, 1995$ and December 31 1 st 2012 with a hospital diagnosis of $A D(n=14,283)$ were matched 1:10 with children without a hospital diagnosis of AD. Endpoints were psychotropic medication use, hospital diagnoses of depression, anxiety, ADHD, or self-harming behavior, accidental/suicidal death, and consultation with a psychiatrist or psychologist. Results: Significant associations were observed between hospital-diagnosed AD and antidepressant [adjusted hazard ratio (aHR) 1.19; 95\% confidence interval (CI) 1.04-1.36], anxiolytic (aHR 1.72; 95\% Cl 1.57-1.90), and centrally acting sympathomimetic (aHR 1.29; 95\% $\mathrm{Cl} 1.18-1.42$ ) medication use. Consultation with a psychiatrist (aHR 1.33; 95\% Cl 1.16-1.52) or psychologist (aHR 1.25; 95\% Cl 1.11-1.41) were also associated with AD. No association with a hospital-diagnosis of depression (aHR 0.58; 95\% Cl 0.21-1.56), anxiety (aHR 1.47; 95\% $\mathrm{Cl} 0.98-2.22$ ) or self-harming behavior (aHR $0.88 ; 95 \% \mathrm{Cl} 0.27-2.88$ ) was observed, but a diagnosis of attention deficit hyperactivity disorder (aHR $1.91 ; 95 \% \mathrm{Cl} 1.56-2.32$ ) was significantly associated with $\mathrm{AD}$. The absolute risks were generally low.

Conclusions: The increased risk of treatment, but not of hospital-diagnosis of psychiatric disorders in children with hospital-diagnosed $A D$, suggests that psychiatric issues in children with $A D$ could be of transient, reversible or mild-moderate nature. 


\section{Introduction}

Atopic dermatitis (AD) is a chronic and relapsing inflammatory skin condition that most often begins in early childhood and affects up to $15 \%$ of children in Denmark ${ }^{1}$. Children with AD suffer from pruritus and interrupted sleep, have a higher risk of social isolation, stigmatization and altered self-esteem ${ }^{2-4}$, and have significantly reduced quality of life ${ }^{5,6}$ with scores being positively correlated with AD severity ${ }^{7}$. While pediatric $A D$ has been shown to be associated with attention deficit hyperactivity disorder $(A D H D)^{8-11}$, the relationship between pediatric $A D$ and other psychiatric disorders is largely unknown ${ }^{12,13}$.

This study investigated whether Danish children with AD seen within the hospital system had increased occurrence of psychiatric diagnoses, psychotropic medication use, consultations with psychologists or psychiatrists, or death from accident or suicide.

\section{Patients and methods}

\section{Data sources}

All Danish citizens are registered in the Civil Registration System ${ }^{14}$ with a personal identification number, enabling linkage across registries. Data on hospital admissions and diagnoses have been registered in the Danish National Patient Registry ${ }^{15}$ since 1978. The diagnostic code for AD has a positive predictive value of $98 \%$ for children in this registry ${ }^{16}$. Systematic studies validating the psychiatric diagnoses in this registry do not exist, however, validation of selected diagnoses, e.g. depression and childhood autism, has been carried out with satisfactory results ${ }^{17-21}$. The Danish National Prescription Registry ${ }^{22}$ contains accurate data on all medications dispensed from pharmacies, registered according to Anatomical Therapeutic Chemical classification. Data are considered both complete and valid from 199522. The Danish National Health Service Register ${ }^{23}$ tracks healthcare services given by all general practitioners and certain medical specialists, including psychiatrists and psychologists. Because the data is connected to reimbursement the coverage is assumed to be very high ${ }^{23}$. Deaths, manner and causes of deaths are registered in the National Causes of Death Registry ${ }^{24}$. Information on tax-reported household income is registered in the Income Statistics Register ${ }^{25}$. All applied administrative codes from registries are presented in Table S3.

\section{Study population}

The source population comprised all children born in Denmark between January $1^{\text {st }}, 1995$ and December $31^{\text {st }}, 2012$. Children were followed until the first of either December $31^{\text {st }}, 2017$, their 18 th birthday, death, emigration, or occurrence of an endpoint. 


\section{Exposure}

Among the source population, we identified all children diagnosed with $A D$ (either in- or outpatient) by a hospital physician between January $1^{\text {st }}, 1995$ and December $31^{\text {st }}, 2012$. Each child with AD was matched by birth date and sex with ten children from the general population without a hospital diagnostic code of $A D$ in the study period (Figure 1). The date of diagnosis of AD served as index date for both the child with $A D$, and the ten reference individuals.

AD severity was modeled as a time-dependent variable (Figure $S 1$ ). Thus, at any given point during followup, $A D$ patients belonged to one of four severity categories according to their prescription data: mild, mild-moderate, moderate-severe, or severe, where a higher category overruled a lower one. Atopic comorbidity status was coded as a time-varying covariate and categorized as I) AD only and II) AD plus asthma/hay fever/food allergy. For classification information see Appendix S1.

\section{Outcomes}

The outcomes included a first-time hospital diagnosis of depression, anxiety, ADHD, or self-harming behavior, a claimed prescription for antidepressants overall (no specific indication), and specifically for depression or anxiety (antidepressants are first-choice treatment for anxiety in children ${ }^{26}$ ), for anxiolytics overall and specifically for anxiety/calming and for centrally acting sympathomimetics (CAS), a consultation with a psychiatrist or psychologist, or a recorded suicide or death from accident (to capture suicides possibly contained in this classification ${ }^{27}$ ).

\section{Other variables}

The children's country of origin was defined by parents' country of birth or country of citizenship and categorized into I) Denmark or II) Other. Socioeconomic status was determined based on household income at child's index date, and the study population was divided into quintiles with $1 / 5$ in each category. Somatic comorbidities included a diagnosis of psoriasis, vitiligo, alopecia areata, autism spectrum disorder, type 1 diabetes, inflammatory bowel disease, or juvenile rheumatoid arthritis, coded as time-dependent variables. The variable asthma/hay fever/food allergy was defined as described in Appendix S1 and coded as a time-dependent variable.

\section{Statistical analyses}

Summary statistics were generated and expressed as median and interquartile range for non-normally distributed continuous variables and frequencies for categorical variables. Chi-square tests (categorical variables), Student's t-test (continuous variables) and Wilcoxon rank-sum test (continuous non-normally 
distributed variables) were performed to compare differences between groups. Cochran-Armitage test for trend was applied to assess ordered categorical variables. Number of events, total risk time, incidence rate (IR) per 10,000 person-years and 95\% confidence interval (CI) for each outcome were calculated. Cox regression models were conducted to estimate adjusted hazard ratios (aHR). Children with a history (event before index) of a studied outcome were excluded in the analysis of that specific outcome. Adjusting covariates were identified as available variables likely being related to both AD status and the outcomes. Model 1 was adjusted for sex, age, socioeconomic status, country of origin, and somatic comorbidities. Model 2 was further adjusted for the variable asthma/hay fever/food allergy. We added interaction terms for the asthma/hay fever/food allergy variable and $A D$ to the models for each outcome. Results were presented according to exposure status, $A D$ severity and atopic comorbidity status (not applicable for model 2). The proportional hazards assumption was graphically assessed using log-log plots. In a sensitivity analysis, we adjusted the risk of psychiatrist consultations for a diagnosis of ADHD as a time-varying covariate. In another sensitivity analysis, we restricted risk time to only include adolescent risk time ( $>10$ years of age).

A p-value $<0.05$ was considered statistically significant. Analyses were performed using SAS software version 9.4 (SAS Institute, Cary, NC, U.S.A.) and Stata/MP version 15 (StataCorp, College Station, TX, U.S.A.).

This study was approved by the Danish Data Protection Agency (journal number VD-2018-286). No approval is required from the National Committee on Health Research Ethics for registry-based research.

\section{Results}

A total of 14,283 children with AD and 142,830 children without AD were included (Table 1). Most participants were males (57.0\%) and the median age at study entry was 1.9 years. More than $80 \%$ of children with $A D$ were diagnosed before age 5 . The majority of children with $A D(57.1 \%)$ were classified as having moderate-severe $A D$ at some point during follow-up, whereas $9.8 \%, 24.1 \%$ and $9.1 \%$ were classified as having mild, mild-moderate and severe disease, respectively. Increased age at index was positively correlated with maximum $A D$ disease severity (2.9 years for severe $A D$ vs. 1.5 years for mild $A D$, $p<0.0001)$. More children without $A D$ than children with $A D$ had Denmark as their country of origin (91.3\% vs. 87.5\%, p<0.0001), and the proportion of ethnic Danes seemed to decrease with increasing maximum $A D$ disease severity $\left(p_{\text {trend }}<0.0001\right)$. The proportion of children with $A D$ decreased with increasing socioeconomic status group ( $p_{\text {trend }}<0.0001$ ). At index, children with AD had a higher prevalence of asthma/hay fever/food allergy $(13.8 \%$ vs. $4.3 \%, p<0.0001)$. 
IRs per 10,000 person-years for all psychiatric outcomes, except a diagnosis of depression and selfharming behavior, were higher for children with AD than children without AD (Table 2). The highest IRs were generally seen for severe $A D$ and for most of the outcomes, IRs increased with increasing $A D$ severity. However, only for a few outcomes the difference between mild AD and severe AD was statistically significant (Table S1). Children with AD with concomitant asthma, hay fever and/or food allergy had higher IRs on all outcomes, except anxiolytic dispensations, than children with AD only (Table S2).

Cox regression models showed no association between $A D$ and a diagnosis of depression (fully adjusted hazard ratio (faHR) $0.50 ; 95 \% \mathrm{Cl} 0.18-1.42$ ), anxiety (faHR 1.29; $95 \% \mathrm{Cl} 0.84-2.00$ ) or self-harming behavior (faHR 0.61; 95\% $\mathrm{Cl} 0.17-2.12$ ). AD was significantly associated with a diagnosis of ADHD (faHR 1.65; 95\% Cl 1.33-2.05) (Table 2). As there were very few suicidal events, no inferential analysis was performed. No significant association was detected between AD and accidental deaths. In the crude and adjusted, but not in the fully adjusted model, AD was significantly associated with a filled prescription of antidepressants overall (aHR 1.19; 95\% Cl 1.04-1.36), and for depression (aHR 1.24; 95\% Cl 1.03-1.48), but not for anxiety (aHR 1.09; 95\% Cl 0.83-1.43). Anxiolytics use overall (faHR 1.60; 95\% Cl 1.44-1.78) and specifically for anxiety/calming (faHR 1.52; $95 \% \mathrm{Cl}$ 1.18-1.96) and filled prescription of CAS (faHR 1.15; $95 \% \mathrm{Cl}$ 1.05-1.27) were all significantly associated with AD. While a significant association was seen between $A D$ and consultation with a psychiatrist (faHR 1.17; $95 \% \mathrm{Cl} 1.01-1.34$ ), the association between $A D$ and a psychologist consultation was attenuated in the fully adjusted model and became nonsignificant (faHR 1.12; $95 \% \mathrm{Cl}$ 0.98-1.26). The addition of interaction terms for the asthma/hay fever/food allergy variable and $A D$ to the models for each outcome, did not show significant interactions except for anxiolytics overall (effect of the asthma/hay fever/food allergy variable was less pronounced in children with $A D)$. In a sensitivity analysis, the risk of psychiatrist consultations was adjusted for a diagnosis of $A D H D$, and the significant association remained present (data not shown).

Limiting the risk time to adolescent time (>10 years) increased and often doubled the IRs of psychiatric outcomes (except regarding ADHD diagnosis and anxiolytic medication use, where the IRs were unchanged and halved, respectively), but did not change the HRs, except regarding ADHD diagnosis and medication use where the significant association in the fully adjusted models was not present (data not shown).

For filled prescriptions of antidepressants and CAS, an AD severity-dependent tendency was seen (Table S1), while the risk of consulting a psychiatrist or psychologist did not seem to depend on AD disease 
severity. For a diagnosis of anxiety, ADHD and use of anxiolytics, the lowest HRs were seen in the mildmoderate group, with the highest risk in the severe group.

Comparing the risk of psychiatric outcomes between children with $A D$ with atopic comorbidities and children with AD only (Table S2) did not show differences in the adjusted model, except regarding psychiatrist consultations, where a higher risk was seen (aHR 1.30; 95\% $\mathrm{Cl} 1.00-1.68$ ).

\section{Discussion}

\section{MAIN FINDINGS}

Higher risks of antidepressant, anxiolytic, and CAS medication use, of consulting a psychiatrist or psychologist, and of being diagnosed with ADHD were observed in children with hospital-diagnosed AD. We found no associations with a hospital-diagnosis of depression, anxiety or self-harming behavior.

\section{INTERPRETATION}

While psychiatric diagnoses among Danish children were generally rare (e.g. anxiety IR 0.1 per 1,000 person-years), psychotropic medication use and consulting a mental health professional were slightly more common, for example CAS and psychologist consultation amounted to an IR of almost 3 and 2 per 1,000 person-years, respectively.

Children with $A D$ had higher risk of receiving treatment (pharmacologically and therapeutically) for psychiatric disorders, but generally not of receiving a hospital-diagnosis of psychiatric disease. This indicates that symptoms of psychiatric disorders in children with $A D$ indeed occur at a higher rate, but also that they may be either adequately treated or not severe or persistent enough to lead to hospital referral and generate a hospital diagnosis. The findings are reminiscent of adult $A D$, where we observed a higher risk of getting diagnosed with psychiatric disease, but this did not lead to hospitalization or suicide $^{28}$.

Pediatric contact to the Danish hospital psychiatry is dominated by ADHD, autism spectrum disorders, and other behavioral and emotional disorders, that accounts for more than $60 \%$ of contacts. Only around $7 \%$ and $4 \%$ have affective disorders and anxiety, respectively ${ }^{29}$, suggesting that these disorders are generally less severe and can be handled by specialists in the private practice sector, that do not report to the Danish National Patient Registry.

Psychiatric disorders are likely underdiagnosed in children, and maybe to a greater extent in subjects with AD. About $41 \%$ of US children presenting to an emergency department with a nonpsychiatric complaint 
screened positive for an undiagnosed psychiatric disorder, with depression being one of the most frequent types ${ }^{30}$. Moreover, a substantial proportion of adult AD patients with elevated anxiety and depression scores were not clinically diagnosed with anxiety or depression ${ }^{31}$ and despite recommendations for increased screening for depression and suicidality in $A D$ patients ${ }^{32,33}$, depression screening is rarely performed ${ }^{33}$. For children with $A D$, it is plausible that physicians ascribe psychiatric symptoms to the patient's skin disorder and await spontaneous improvement in AD with age or following effective therapy and hope that mental health will improve simultaneously. Clinical trials have shown that a reduction in $A D$ severity correlates well with improvement in quality of life scores and decrease in anxiety and depression scores in turn indicating that these symptoms are reversible ${ }^{34,35}$. Unfortunately, however, the quality of life outcomes typically used tend to be insufficiently sensitive to change ${ }^{36,37}$, making it difficult to measure the true effect of $A D$ treatment on the psychiatric symptoms.

Associations seen in previous studies between $A D$ and diagnoses of depression, anxiety and self-harming behavior were not observed in this study, but it did confirm the increased risk of a diagnosis of ADHD ${ }^{8-11}$. Recently, three meta-analyses reported pooled ORs of $1.27(95 \% \mathrm{Cl} 1.12-1.45)^{12}, 1.40(95 \% \mathrm{Cl}, 1.26-$ $1.57)^{38}$ and $1.31(95 \% \mathrm{Cl} 0.99-1.75)^{13}$ regarding the association between pediatric $A D$ and depression. Importantly, many included studies used self-reported information on depression/depressive symptoms instead of clinical diagnoses as in our study ${ }^{39-41}$. A recent meta-analysis found a significant association between childhood AD and anxiety (OR 1.34; 95\% $\mathrm{Cl} 1.06-1.69)^{38}$, but included 7 studies of which only two, that used parental report of mental health problems and behavior, gave significant associations. Higher odds of self-reported suicide attempt (aOR 1.31; $95 \% \mathrm{Cl} 1.12-1.52)$ was found in a study on adolescents ${ }^{41}$.

A positive association between $A D$ and antidepressant use was present in the current analysis, contrasting a Swedish study ${ }^{42}$ that reported no association. This may in part be explained by their study population including $A D$ children from both primary and secondary care and use of parental reports of eczema leading to a prevalence of $33 \%$ indicating potential misclassification and hence dilution of the association. The increased risk of anxiolytic medication use in adults with $A D^{28}$, was confirmed among Danish children with $A D$, and the association remained present after restricting indications to 'for anxiety'/'calming'/'for unrest'. No association between $A D$ and medications for ADHD at school age was found in Swedish children ${ }^{42}$, but we confirmed the association seen in a previous Danish study9.

A cohort study of 266,182 subjects $^{43}$ found that patients ( $<20$ years) with $A D$ had a significantly increased risk of psychiatric consultations (aHR 3.29; 95\% Cl 3.16-3.42). Our estimate remained significant after 
adjusting the risk for a diagnosis of ADHD, suggesting that the increased risk was not explained by the increased occurrence of ADHD.

Stratifying results according to $A D$ disease severity did not reveal any clear tendencies regarding severity dependency. This could simply be due to risk of psychiatric disorders and medication use not being affected by the severity of disease, or that severity categorization was insufficient and led to misclassification. Unfortunately, we did not have access to clinical information about AD severity. Children with $A D$ with atopic comorbidities did not seem to have higher risk of psychiatric outcomes, except a $30 \%$ increased risk of a psychiatrist consultation, when compared to children with AD without atopic comorbidities. AD, hay fever, food allergy and allergic asthma may be seen as belonging to the same disease spectrum as they share the same type 2 inflammation and very often co-exist as the atopic triad ${ }^{44}$. A holistic disease understanding would argue against adjustment for atopic comorbidities as the diseases should be studied as one single entity. However, when we adjusted our analyses for the variable asthma/hay fever/food allergy the association with antidepressant use and psychologist consultations disappeared in turn suggesting that these associations cannot be explained by $A D$ alone, but rather the coexistence with atopic comorbidity.

Although the present study found $A D$ to be significantly associated with psychiatric issues, the absolute risk was generally low, and the excess risk seen in $A D$ patients amounted to less than 2 events per 1,000 children with $A D$ per year. Since our outcome definitions were much more stringent than those used in previous publications, it seems possible that psychiatric problems in pediatric AD patients are of a transient or reversible nature and few are of severe, persistent and chronic type that would lead to management by hospital psychiatrists. This, however, could not be clarified from analyses on prescription data, as children with AD had significantly fewer courses of antidepressants and slightly fewer dispensations in each course, but at the same time had more courses and more filled prescriptions in each course of anxiolytics. Another possible explanation for our results, that is difficult to rule out, is findings simply being a marker of increased health care consumption in AD patients.

\section{STRENGTHS AND LIMITATIONS}

Strengths of this study include the use and combination of large, nationwide registries with virtually complete data and a long follow-up period. We used a validated definition of $A D^{16}$, including only hospitaldiagnosed $A D$, why findings cannot be generalized to children seen in a primary care setting. Despite the use of nationwide registries, absolute event numbers were low in turn reducing the precision of the estimates as well as the absolute risk of these events. While we attempted to stratify on AD severity and 
atopic comorbidity status, these variables are proxies based on e.g. medication use, and misclassification is therefore possible. Some error must be expected when using the prescriber's indication for giving a medication, since default indications may be accepted by physicians. Another concern regarding severity categorization based on prescription data is that stronger $A D$ treatment choices are more likely with increasing age, and the probability of psychiatric outcomes in childhood also being higher in older ages.

This could cause overestimation of the importance of AD severity. Increased contact with the health care system and thereby earlier diagnosis of psychiatric illnesses in the AD group cannot be completely ruled out.

\section{CONCLUSION}

Children with hospital-diagnosed AD had increased risk of receiving a prescription for psychiatric symptoms, but this did not lead to a hospital-diagnosis of a psychiatric disorder. These findings suggest that psychiatric issues in children with $A D$ could be of transient, reversible or mild-moderate nature that for most can be handled in the primary healthcare sector and does not lead to specialist hospital care.

\section{References}

1 Hammer-Helmich L, Linneberg A, Thomsen SF, Glümer C. Association between parental socioeconomic position and prevalence of asthma, atopic eczema and hay fever in children. Scand J Public Health 2014; 42:120-7.

2 Lewis-Jones S. Quality of life and childhood atopic dermatitis: the misery of living with childhood eczema. Int J Clin Pract 2006; 60:984-92.

3 Brenninkmeijer EEA, Legierse CM, Sillevis Smitt JH, et al. The course of life of patients with childhood atopic dermatitis. Pediatr Dermatol 2009; 26:14-22.

$4 \quad$ Chernyshov P V. Stigmatization and self-perception in children with atopic dermatitis. Clin Cosmet Investig Dermatol 2016; 9:159-66.

5 Holm EA, Wulf HC, Stegmann H, Jemec GBE. Life quality assessment among patients with atopic eczema. Br J Dermatol 2006; 154:719-25.

6 Beattie PE, Lewis-Jones MS. A comparative study of impairment of quality of life in children with skin disease and children with other chronic childhood diseases. Br J Dermatol 2006; 155:145-51. Ben-Gashir MA, Seed PT, Hay RJ. Quality of life and disease severity are correlated in children with atopic dermatitis. Br J Dermatol 2004; 150:284-90. 
Strom MA, Fishbein AB, Paller AS, Silverberg Jl. Association between atopic dermatitis and attention deficit hyperactivity disorder in U.S. children and adults. Br J Dermatol 2016; 175:920-9. Lindorff Riis J, Vestergaard C, Deleuran MS, Olsen M. Childhood atopic dermatitis and risk of attention deficit/hyperactivity disorder: A cohort study. J Allergy Clin Immunol 2016; 138:608-10.

Paller A, Jaworski JC, Simpson EL, et al. Major Comorbidities of Atopic Dermatitis: Beyond Allergic Disorders. Am J Clin Dermatol 2018; 19:821-38.

Lee $\mathrm{CY}$, Chen $\mathrm{MH}$, Jeng $\mathrm{MJ}$, et al. Longitudinal association between early atopic dermatitis and subsequent attention-deficit or autistic disorder A population-based case-control study. Medicine (Baltimore) 2016; 95:e5005.

Rønnstad ATM, Halling-Overgaard AS, Hamann CR, et al. Association of atopic dermatitis with depression, anxiety, and suicidal ideation in children and adults: A systematic review and metaanalysis. J Am Acad Dermatol 2018; 79:448-456.e30.

Patel KR, Immaneni S, Singam V, et al. Association between atopic dermatitis, depression, and suicidal ideation: A systematic review and meta-analysis. J Am Acad Dermatol 2019; 80:402-10.

Schmidt M, Pedersen L, Sørensen HT. The Danish Civil Registration System as a tool in epidemiology. Eur J Epidemiol 2014; 29:541-9.

Schmidt M, Schmidt SAJ, Sandegaard JL, et al. The Danish National Patient Registry: a review of content, data quality, and research potential. Clin Epidemiol 2015; 7:449-90.

Andersen YMF, Egeberg A, Skov L, Thyssen JP. Demographics, healthcare utilization and drug use in children and adults with atopic dermatitis in Denmark: a population-based cross-sectional study. $J$ Eur Acad Dermatology Venereol 2019; 33:1133-42.

Mors O, Perto GP, Mortensen PB. The Danish psychiatric central research register. Scand J Public Health 2011; 39:54-7.

Bock C, Bukh J, Vinberg M, et al. Validity of the diagnosis of a single depressive episode in a case register. Clin Pract Epidemiol Ment Heal 2009; 5:4.

Phung TKT, Andersen BB, Høgh P, et al. Validity of dementia diagnoses in the Danish hospital registers. Dement Geriatr Cogn Disord 2007; 24:220-8.

Uggerby $P, \varnothing$ stergaard SD, Røge R, et al. The validity of the schizophrenia diagnosis in the Danish 
Psychiatric central research register is good. Dan Med J 2013; 60:A4578.

21 Lauritsen MB, Jørgensen M, Madsen KM, et al. Validity of Childhood Autism in the Danish Psychiatric Central Register: Findings from a Cohort Sample Born 1990-1999. J Autism Dev Disord 2010; 40:139-48.

Pottegård A, Schmidt SAJ, Wallach-Kildemoes $\mathrm{H}$, et al. Data resource profile: The Danish national prescription registry. Int J Epidemiol 2017; 46:798-798f.

Sahl Andersen J, De Fine Olivarius N, Krasnik A. The Danish National Health Service Register. Scand J Public Health 2011; 39:34-7.

Helweg-Larsen K. The Danish Register of Causes of Death. Scand J Public Health 2011; 39:26-9.

Baadsgaard M, Quitzau J. Danish registers on personal income and transfer payments. Scand J Public Health 2011; 39:103-5.

Danish Health Authority. [Guidance on the medical treatment of children and adolescents with mental disorders]. 2019. URL https://www.retsinformation.dk/Forms/R0710.aspx?id=210034.

27 Hawton K, Bale L, Brand F, et al. Mortality in children and adolescents following presentation to hospital after non-fatal self-harm in the Multicentre Study of Self-harm: a prospective observational cohort study. Lancet Child Adolesc Heal 2020; 4:111-20.

28 Thyssen JP, Hamann CR, Linneberg A, et al. Atopic dermatitis is associated with anxiety, depression, and suicidal ideation, but not with psychiatric hospitalization or suicide. Allergy 2018; 73:214-20.

29 Ministry of Health and Elderly Affairs. [Demographic and socioeconomic differences in the contact pattern to the psychiatry]. 2018. URL https://bedrepsykiatri.dk/wpcontent/uploads/2019/09/Analyse-Demografiske-og-sociooekonomiske-forskelle-ikontaktmoenstret-til-psykiatrien-1.pdf.

30 Downey LVA, Zun LS. Identifying Undiagnosed Pediatric Mental Illness in the Emergency Department. Pediatr Emerg Care 2018; 34:e21-3.

31 Silverberg JI, Gelfand JM, Margolis DJ, et al. Symptoms and diagnosis of anxiety and depression in atopic dermatitis in U.S. adults. Br J Dermatol 2019; 181:554-65. 
depression and suicidal ideation. JAMA Dermatology. 2018; 154:139-41.

33

34

35

Singh P, Silverberg JI. Underscreening of depression in U.S outpatients with atopic dermatitis and psoriasis. Br J Dermatol 2019; [Epub ahead of print].

Tsianakas A, Luger TA, Radin A. Dupilumab treatment improves quality of life in adult patients with moderate-to-severe atopic dermatitis: results from a randomized, placebo-controlled clinical trial. Br J Dermatol 2018; 178:406-14.

Cork MJ, Eckert L, Simpson EL, et al. Dupilumab improves patient-reported symptoms of atopic dermatitis, symptoms of anxiety and depression, and health-related quality of life in moderate-tosevere atopic dermatitis: analysis of pooled data from the randomized trials SOLO 1 and SOLO 2.J Dermatolog Treat 2019; [Epub ahead of print].

Gabes M, Tischer C, Apfelbacher C. Measurement properties of quality-of-life outcome measures for children and adults with eczema: An updated systematic review. Pediatr Allergy Immunol 2020; 31:66-77.

Chalmers JR, Thomas KS, Apfelbacher C, et al. Report from the fifth international consensus meeting to harmonize core outcome measures for atopic eczema/dermatitis clinical trials (HOME initiative). Br J Dermatol 2018; 178:e332-41.

Xie QW, Xiaolu D, Tang X, et al. Risk of mental disorders in children and adolescents with atopic dermatitis: A systematic review and meta analysis. Front Psychol 2019; 10:1773.

Yaghmaie P, Koudelka CW, Simpson EL. Mental health comorbidity in patients with atopic dermatitis. J Allergy Clin Immunol 2013; 131:428-33.

Augustin M, Radtke MA, Glaeske G, et al. Epidemiology and Comorbidity in Children with Psoriasis and Atopic Eczema. Dermatology 2015; 231:35-40.

Lee $\mathrm{S}$, Shin A. Association of atopic dermatitis with depressive symptoms and suicidal behaviors among adolescents in Korea: the 2013 Korean Youth Risk Behavior Survey. BMC Psychiatry 2017; $17: 3$.

Johansson EK, Ballardini N, Kull I, et al. Association between preschool eczema and medication for attention-deficit/hyperactivity disorder in school age. Pediatr Allergy Immunol 2017; 28:44-50.

Shin J, Choi Y, Park E-C, et al. Psychiatry outpatient visits by atopic dermatitis patients varying in 
the complexity of their prescriptions: A nationwide cohort study conducted from 2005 to 2013. Medicine (Baltimore) 2016; 95:e5411.

Lloyd C, RJ S. Type 2 immunity: Expanding our view. Sci Immunol 2018; 3.

45 Page PM, Broek JL, Bousquet J, et al. Global Strategy for Asthma Management and Prevention. 2017. URL https://ginasthma.org/wp-content/uploads/2017/02/wmsGINA-2017-main-reportfinal_V2.pdf. Bønnelykke K, Pedersen S, Rubak SLM, et al. [Childhood asthma: Danish guidelines for diagnosis and treatment]. Ugeskr læger 2013; 175:1863-7.

47 Stensballe LG, Klans $\varnothing$ L, Jensen A, et al. The validity of register data to identify children with atopic dermatitis, asthma or allergic rhinoconjunctivitis. Pediatr Allergy Immunol 2017; 28:535-42.

48 Örtqvist AK, Lundholm C, Wettermark B, et al. Validation of asthma and eczema in populationbased Swedish drug and patient registers. Pharmacoepidemiol Drug Saf 2013; 22:850-60. 
Table 1. Demographic characteristics of children with atopic dermatitis (AD) stratified by AD disease severity and children without $A D$

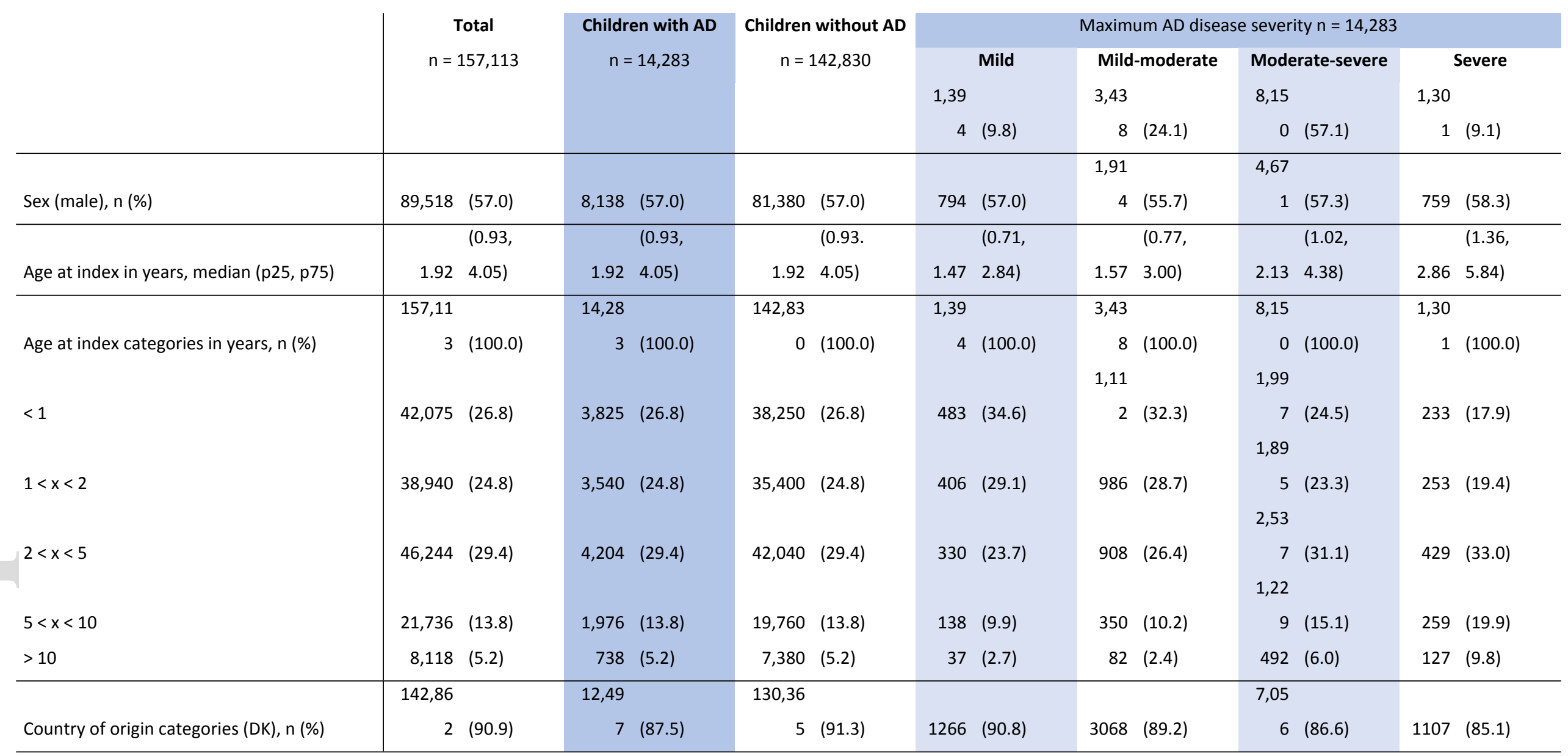




\begin{tabular}{|c|c|c|c|c|c|c|c|c|}
\hline & 156,80 & 14,27 & 142,52 & & & & & \\
\hline Socioeconomic status, n (\%) & $0 \quad(99.8)$ & $7(100.0)$ & 3 & (99.8) & & & & \\
\hline Lowest & $31,359 \quad(20.0)$ & $3,058 \quad(21.4)$ & 28,301 & $(19.9)$ & & & & \\
\hline Below average & $31,361 \quad(20.0)$ & $2,986 \quad(20.9)$ & 28,375 & $(19.9)$ & & & & \\
\hline Average & $31,361 \quad(20.0)$ & $2,757 \quad(19.3)$ & 28,604 & (20.1) & & & & \\
\hline Above average & $31,359 \quad(20.0)$ & 2,754 (19.3) & 28,605 & (20.1) & & & & \\
\hline Highest & $31,360 \quad(20.0)$ & 2,722 & 28,638 & (20.1) & & & & \\
\hline Missing & $313(0.20)$ & $6(0.04)$ & 307 & $(0.21)$ & & & & \\
\hline Asthma/hay fever/food allergy at index, $n$ & & & & & & & 1,10 & \\
\hline (\%) & $8,128 \quad(5.2)$ & $1,978 \quad(13.8)$ & 6,150 & (4.3) & $184(13.2)$ & 463 (13.5) & $5(13.6)$ & $226(17.4$ \\
\hline
\end{tabular}

$A D=$ atopic dermatitis; $n=$ number; $p 25,25$ th percentile; $p 75,75$ th percentile; SD, standard deviation, $D K=$ Denmark. AD disease severity was categorized based on prescription data. 
Table 2. Number of events, total risk time, incidence rate (IR) per 10,000 person-years and hazard ratios (HR) with 95\% confidence intervals $(\mathrm{Cl})$ of the examined outcomes in patients with atopic dermatitis (AD) compared with children without AD.

\begin{tabular}{|c|c|c|c|c|c|c|c|c|c|c|c|c|c|}
\hline & \multirow[b]{2}{*}{ Risk } & \multirow[b]{2}{*}{ Event } & \multirow[b]{2}{*}{ IR } & \multirow[b]{2}{*}{$95 \% \mathrm{Cl}$} & \multicolumn{3}{|c|}{ Crude model } & \multicolumn{3}{|c|}{ Model 1} & \multicolumn{3}{|c|}{ Model 2} \\
\hline & & & & & HR & $95 \% \mathrm{Cl}$ & p & $\mathrm{aH}$ & $95 \% \mathrm{Cl}$ & p & $\mathrm{faH}$ & $95 \% \mathrm{Cl}$ & $\mathbf{p}$ \\
\hline \multicolumn{14}{|l|}{ Depression } \\
\hline Children without $A D$ & $1,611,60$ & 71 & 0.44 & $(0.35-0.56)$ & ref & & & & & & & & \\
\hline Children with $A D$ & 162,117 & 5 & 0.31 & $(0.13-0.74)$ & 0.7 & $(0.28-$ & 0.45 & 0.5 & (0.21- & 0.27 & 0.50 & $(0.18-$ & 0.19 \\
\hline \multicolumn{14}{|l|}{ Anxiety } \\
\hline Children without $A D$ & $1,611,26$ & 180 & 1.12 & $(0.97-1.29)$ & ref & & & & & & & & \\
\hline Children with & 162,050 & 27 & 1.67 & $(1.14-2.43)$ & 1.4 & $(1.00-$ & 0.05 & 1.4 & $(0.98-$ & 0.06 & 1.29 & $(0.84-$ & 0.24 \\
\hline \multicolumn{14}{|l|}{ ADHD } \\
\hline Children without $A D$ & $1,606,02$ & 650 & 4.05 & $(3.75-4.37)$ & ref & & & & & & & & \\
\hline Children with & 161,076 & 123 & 7.64 & $(6.40-9.11)$ & 1.8 & $(1.56-$ & 0.00 & 1.9 & $(1.56-$ & 0.00 & 1.65 & $(1.33-$ & 0.00 \\
\hline \multicolumn{14}{|l|}{ Self-harming behavior } \\
\hline Children without $A D$ & $1,611,71$ & 35 & 0.22 & $(0.16-0.30)$ & ref & & & & & & & & \\
\hline Children with $A D$ & 162,127 & 3 & 0.19 & $(0.06-0.57)$ & 0.8 & $(0.26-$ & 0.80 & 0.8 & (0.27- & 0.82 & 0.61 & (0.17- & 0.43 \\
\hline \multicolumn{14}{|l|}{ Suicide } \\
\hline 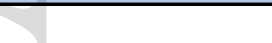 & \multicolumn{13}{|c|}{$\mathrm{N} / \mathrm{A}$} \\
\hline \multicolumn{14}{|l|}{ Death from accident } \\
\hline Children without $A D$ & $1,611,79$ & 34 & 0.21 & $(0.15-0.30)$ & ref & & & & & & & & \\
\hline Children with & 162,133 & 4 & 0.25 & $(0.09-0.66)$ & 1.1 & $(0.42-$ & 0.76 & 1.0 & $(0.38-$ & 0.87 & 1.02 & $(0.33-$ & 0.97 \\
\hline \multicolumn{14}{|l|}{ Antidepressants } \\
\hline Children without $A D$ & $1,604,81$ & 2082 & 12.9 & (12.43- & ref & & & & & & & & \\
\hline Children with & 161,308 & 243 & 15.0 & (13.28- & 1.1 & (1.03- & 0.01 & 1.1 & (1.04- & 0.01 & 1.05 & (0.91- & 0.48 \\
\hline \multicolumn{14}{|c|}{ Antidepressants for depression } \\
\hline Children without $A D$ & $1,608,00$ & 1122 & 6.98 & $(6.58-7.40)$ & ref & & & & & & & & \\
\hline Children with & 161,693 & 134 & 8.29 & (7.00-9.82) & 1.2 & $(1.01-$ & 0.04 & 1.2 & $(1.03-$ & 0.02 & 1.10 & $(0.91-$ & 0.31 \\
\hline \multicolumn{14}{|c|}{ Antidepressants for anxiety } \\
\hline Children without $A D$ & $1,608,97$ & 545 & 3.39 & $(3.11-3.68)$ & ref & & & & & & & & \\
\hline Children with & 161,856 & 59 & 3.65 & $(2.82-4.70)$ & 1.0 & $(0.83-$ & 0.53 & 1.0 & $(0.83-$ & 0.55 & 0.94 & $(0.71-$ & 0.68 \\
\hline \multicolumn{14}{|l|}{ Anxiolytics } \\
\hline Children without $A D$ & $1,512,70$ & 2871 & 18.9 & $(18.30-$ & ref & & & & & & & & \\
\hline Children with & 152,606 & 501 & 32.8 & (30.08- & 1.7 & $(1.57-$ & 0.00 & 1.7 & $(1.57-$ & 0.00 & 1.60 & $(1.44-$ & 0.00 \\
\hline \multicolumn{14}{|c|}{ Anxiolytics for anxiety/calming } \\
\hline Children without $A D$ & $1,537,97$ & 489 & 3.18 & (2.91-3.47) & ref & & & & & & & & \\
\hline Children with & 157,248 & 81 & 5.15 & $(4.14-6.40)$ & 1.6 & $(1.29-$ & 0.00 & 1.6 & $(1.33-$ & 0.00 & 1.52 & $(1.18-$ & 0.00 \\
\hline \multicolumn{14}{|c|}{ Centrally acting sympathomimetics } \\
\hline Children without $A D$ & $1,587,93$ & 4253 & 26.7 & (25.99- & ref & & & & & & & & \\
\hline Children with & 159,147 & 545 & 34.2 & (31.49- & 1.2 & $(1.18-$ & 0.00 & 1.2 & (1.18- & 0.00 & 1.15 & $(1.05-$ & 0.00 \\
\hline \multicolumn{14}{|l|}{ Psychiatrist consultation } \\
\hline Children without $A D$ & $1,601,89$ & 1882 & 11.7 & (11.23- & ref & & & & & & & & \\
\hline Children with & 160,971 & 246 & 15.2 & (13.49- & 1.3 & (1.14- & 0.00 & 1.3 & $(1.16-$ & 0.00 & 1.17 & (1.01- & 0.03 \\
\hline Psychologist consultati & & & & & & & & & & & & & \\
\hline Children without AD & $1,601,07$ & 2581 & 16.1 & (15.51- & ref & & & & & & & & \\
\hline
\end{tabular}


$A D=$ atopic dermatitis; $I R=$ incidence rate, $H R=$ hazard ratio, $\mathrm{Cl}$ = confidence interval. Model 1 was adjusted for sex, age, socioeconomic status, country of origin and somatic comorbidities. Model 2 was further adjusted for asthma/hay fever/food allergy. Bold marking indicates statistical significance. 


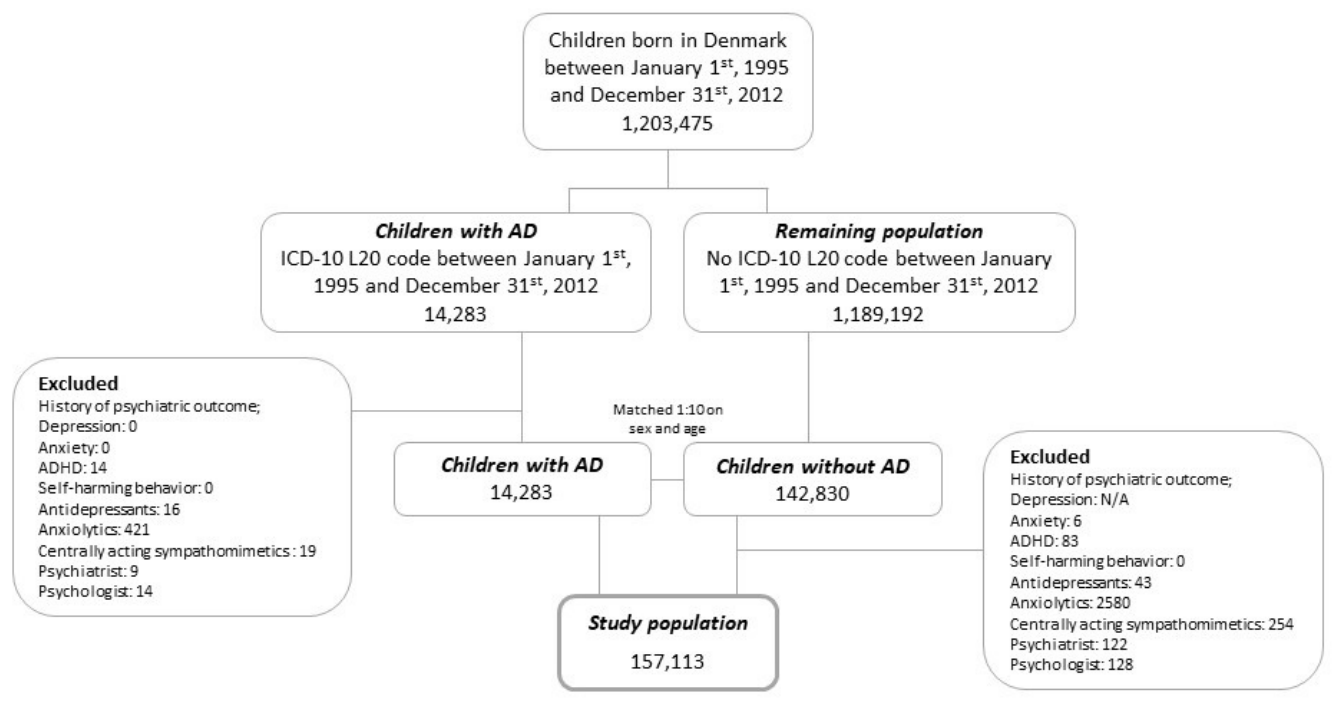

bjd_19817_f1.jpg

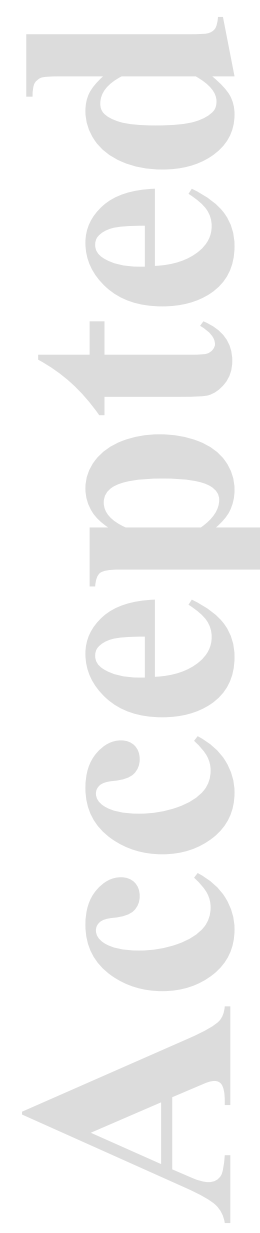

